\title{
Data Flow-Related Provisions in Preferential Trade Agreements
}

Trends and Patterns of Diffusion

Manfred Elsig and Sebastian Klotz*

\section{A INTRODUCTION}

Innovation in information and communication technology (ICT) has been one of the key drivers of economic globalization. As a result, the volume of goods and services and, therefore, cross-border data flows have been increasing at an exceptional speed. The World Trade Organization (WTO) and its members have early on realized the importance of establishing global rules for guiding these processes. Already at its Second Ministerial Conference in 1998, the WTO adopted the Declaration on Global Electronic Commerce and called for the establishment of a work programme on e-commerce. The work programme has been implemented by four of the WTO's bodies which have regularly reported on the developments, ${ }^{1}$ and the General Council has periodically reviewed the progress of the programme. Based on the minutes of the meetings of the General Council, Figure 2.1 maps the number of interventions by WTO members related to the topic of e-commerce. The data shows important variation in terms of attention given to the topic over time. After a substantial interest on e-commerce-related issues in the late 1990 and the early 2000 , the preoccupation with the topic dropped dramatically from 2003 until around 2011. Overall attention has only picked up again in the past few years. In preparation for the Eleventh Ministerial Conference (MC11) in Buenos Aires in December 2017, e-commerce was back on the table and the subject of many of the interventions made in the General Council.

\footnotetext{
Manfred Elsig is Professor of International Relations and Deputy Managing Director and Director of Research of the World Trade Institute, University of Bern. Contact: manfred .elsig@wti.org. Sebastian Klotz is a doctoral fellow at the World Trade Institute, University of Bern and a visiting researcher at the University of Oxford. Contact: sebastian.klotz@wti.org.

1 These bodies include the Council for Trade in Services, the Council for Trade in Goods, the Council for Trade-Related Aspects of Intellectual Property Rights (TRIPS), the Committee on Trade and Development; for details on the work by these bodies and updates, see www.wto.org/ english/tratop_e/ecom_e/ecom_e.htm.
} 


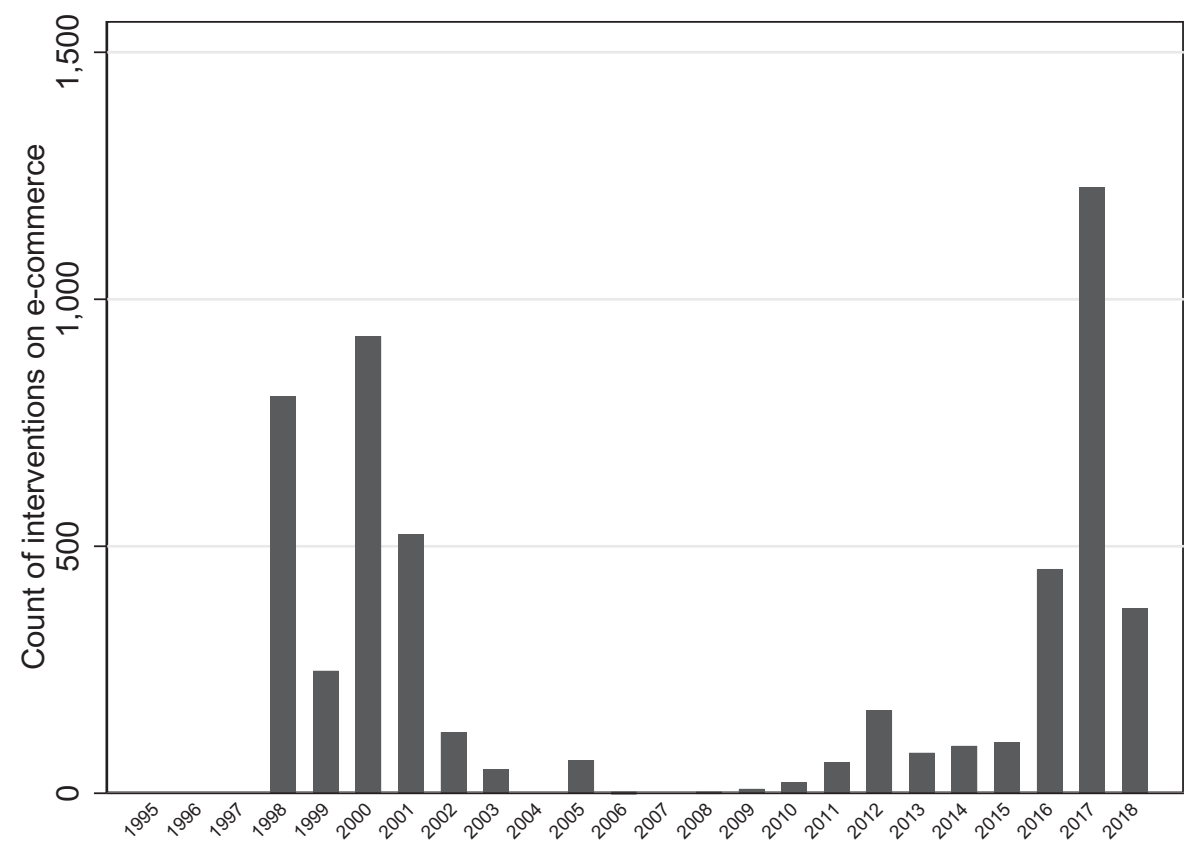

FIGURE 2.1. Interventions on e-commerce in the WTO General Council, 1995-2018 Source: Authors' illustration based on the WTO General Council meeting minutes (WT/GC/M/1-WT/ GC/M/174) available on the WTO website.

Following intensified discussions, seventy-six WTO members issued a joint statement on e-commerce during the World Economic Forum meeting in Davos in January 2019 in which they 'confirm [their] intention to commence WTO negotiations on trade-related aspects of electronic commerce', 'seek to achieve a high standard outcome that builds on existing WTO agreements and frameworks with the participation of as many WTO Members as possible' and 'continue to encourage all WTO Members to participate in order to further enhance the benefits of electronic commerce for businesses, consumers and the global economy. ${ }^{2}$

Notwithstanding the newly found interest in e-commerce topics at the multilateral level, we observe that the WTO has been rather passive in its approach to address the data-related changes in the world economy. If regulatory solutions have been promoted, it was mostly driven by unilateral or extraterritorial approaches by the main trading powers. Given the absence of progress in rule-making in the WTO for some time now and a growing set of unilateral policies, the negotiators of preferential trade agreements (PTAs) have themselves attempted to shape the rule book for the twenty-first-century world economy - rules that would address needs resulting from an ever more integrated and data-driven economy. The first PTA that 
had an electronic-commerce provision was the Jordan-US PTA in 2000 and the first data flow provisions go back to the Korea-US PTA concluded in 2007. So, these types of provisions are a rather recent phenomenon in trade agreements, but it clearly shows that WTO members have shifted the venue for rule-making from the WTO to the world of PTAs starting in the early zooos. ${ }^{3}$

This chapter focuses on data-related provisions in PTAs and explores trends and patterns over time. We attempt to map clusters and models that have emerged. Related to this, we also focus on who the 'rule-makers' are in this regulatory area. If PTAs are best understood as 'laboratories' for global rule-making, we investigate in this chapter which governments are pivotal in pushing regulatory ideas and templates.

The chapter is organized as follows: first, we provide a short discussion of the literature that provides the backbone and rationale for the data collection. We then present particular indicators aggregated from the data that attempt to capture various salient dimensions of data flow-related provisions in PTAs. This is followed by an enquiry into the trends over time using these indicators, exploring the rule-makers' roles through both text-as-data analyses and manual coding of data-related design features. Finally, we graphically explore bivariate relationships that speak to potential explanations why we would expect to see variation in PTA design in this domain. The chapter concludes by outlining possible next research avenues in the area of digital trade governance.

\section{B A LOOK AT STATE OF THE ART}

Various strands of literature in international relations and political economy provide the backbone for collecting and analyzing PTA design features - some of them address general debates regarding the move towards more law, the relationship between multilateralism and regionalism or on rule-making versus rule-taking, the role of diffusion and debates specific to data flows and regulatory responses. We have mapped some of these debates in this chapter.

The call for more fine-grained information on the content of international agreements has been around for quite a while. Both the legalization as well as the rational design literatures provide useful guidance for choosing the types of design features to focus on. ${ }^{4}$ Both literatures develop indicators and propose measures to account for treaties' scope, degree of obligation as well as flexibility features. In particular in the trade literature on PTAs, various indicators have been further developed - such as with regard to the depth of an agreement which captures the

3 See Chapter 1 in this volume for more details.

4 J. Goldstein et al., 'Introduction: Legalization and World Politics', International Organization 54 (2000), 385-399; B. Koremenos, C. Lipson and D. Snidal, "The Rational Design of International Institutions', International Organization 55 (2001), 761-799. 
degree to which measures may lead to increased market integration ${ }^{5}$ or with regard to various types of flexibility tools which allow for legally imposing barriers, normally for a limited period of time. ${ }^{6}$ These conceptualizations are also insightful when mapping data flow provisions as part of PTAs.

Another strand of literature to which this chapter speaks is the work on regime complexity, which is usually defined as a set of non-hierarchical overlapping institutions. ${ }^{7}$ The universe of PTAs with over one thousand agreements, where all WTO members are participating actors, serves as an interesting laboratory of how regime complexity affects the behaviour of states both in collaborative and conflictive fashions. Linked to the concept of regime complexity is the emerging attention given to diffusion drivers and effects, ${ }^{8}$ which asks the essential questions of why states sign PTAs; what the role of competition with other trading nations is; how learning and mimicking from neighbouring countries impact the decision to engage in PTAs, or whether PTA signature and the treaty commitments are a result of coercion by powerful states that aim to have their templates and models reflected in as many treaties as possible. Both, the regime complexity theories and diffusion theories, provide strong testimony to how international treaties are interdependent and serve as a cautionary note of analyzing single agreements in isolation of other treaties. Within the study of international institutions and international trade, additional debates have emerged, focusing on the groups of countries that promote their own rules ('rule-makers') and the ones that are on the receiving end of global regulation ('rule-takers'). This chapter focuses on the conditions under which rules diffuse using a mix of methods, including textual analyses. ${ }^{9}$

Finally, research on trade and data flows can build on the work that has zoomed in on the relationship between the promotion of liberalization and a government's objective to protect public interests. While the early trade literature focused on various linkages, such as trade and human rights and trade and environment, ${ }^{10}$ more recently

5 A. Dür, L. Baccini and M. Elsig, "The Design of International Trade Agreements: Introducing a New Dataset', The Review of International Organizations 9 (2014), 353-375.

6 L. Baccini, A. Dür and M. Elsig, "The Politics of Trade Agreement Design: Revisiting the Depth-Flexibility Nexus', International Studies Quarterly 59 (2015), 765-775.

7 D. W. Drezner (ed), All Politics Is Global: Explaining International Regulatory Regimes (Princeton, NJ: Princeton University Press, 2007); K. J. Alter and K. Raustiala, "The Rise of International Regime Complexity', Annual Review of Law and Social Science 14 (2018), 329-349.

8 B. A. Simmons, F. Dobbin and G. Garrett, 'Introduction: The International Diffusion of Liberalism', International Organization 6o (2006), 781-810; F. Gilardi, 'Transnational Diffusion: Norms, Ideas and Policies', in T. Risse, W. Carlsnaes and B. A. Simmons (eds), Handbook of International Relations (Thousand Oaks, CA: SAGE Publications, 2012), 453-477.

9 W. Alschner and D. Skougarevskiy, 'Mapping the Universe of International Investment Agreements', Journal of International Economic Law 19 (2016), 561-688.

10 E. M. Hafner-Burton, 'Trading Human Rights: How Preferential Trade Agreements Influence Government Repression', International Organization 59 (2005), 593-629; T. Bernauer and Q. 
the concept of optimal protection of individual rights related to data protection has become more central. Following the old idea of 'embedded liberalism', ${ }^{11}$ we are interested in how liberalization in data flows related to trade and services goes hand in hand with governments' demands for flexibility or escape instruments to protect citizens' interests in terms of privacy, and therefore pursuing social goals.

\section{DESIGN DIMENSIONS AND RELATED CONCEPTS}

In recent years, research on trade agreements has made substantial progress by unpacking the various design features in PTAs to explore variation across treaties. ${ }^{12}$ We follow this work by zooming in on data-relevant provisions. The data presented below is based on seventy-four single variables focusing, on the one hand, on the electronic commerce chapters and, on the other hand, on data-relevant provisions in other PTA chapters, including services, intellectual property rights and specific rules on ICT, data localization and similar content. The data is then aggregated to produce a number of indicators measuring various key dimensions derived from the earlier literature discussion. In the following, we briefly describe the different concepts and the types of variables that we draw upon to construct these.

\section{Scope}

This concept measures the attention paid to data-related provisions. Scope is different from depth, as it does not capture the degree of obligation and commitment, but rather provides information about the extent to which the topic is covered within the agreement. ${ }^{13}$ Therefore, we construct two different measures for scope or coverage: Scope 1 is the word count for the electronic commerce chapter; scope 2 is the number of total provisions found in the electronic commerce chapter. Scope 1 has a maximum of 3,206 words and the average value is 793. Scope 2 is an additive index which ranges from $\circ$ to 74 .

\section{Depth of Data Flow Facilitation}

This measure comes closest to what is in the literature described as the depth of the agreement. ${ }^{14}$ In this case, depth is thought of in relation to commitments, which

Nguyen, 'Free Trade and/or Environment Protection?', Global Environmental Politics 15 (2015), 105-129.

${ }^{11}$ J. G. Ruggie, 'International Regimes, Transactions, and Change: Embedded Liberalism in the

Postwar Economic Order', International Organization 36 (1982), 379-415.

${ }_{12}$ Dür et al., note 5 .

${ }_{13}$ Koremenos et al., note 4.

${ }^{14}$ G. W. Downs, D. M. Rocke and P. N. Barsoom, 'Is the Good News about Compliance Good News for Cooperation?', International Organization 52 (1996), 379-406; Dür et al., note 5. 
tend to make trading easier when data transfer is involved. Here we create an additive index of seventeen variables that include rules for facilitating trade and providing for a regulatory environment to foster trade in data - these range from free movement of data commitments, promoting paperless trading and electronic signatures, and advocating self-regulation of the private sector to abstain from data localization measures. This additive indicator ranges from $\circ$ to 17 .

\section{Flexibility}

As the literature on international institutions suggests that deeper commitments are also more flexible, ${ }^{15}$ we constructed one indicator that focuses on eight escape and flexibility measures that we detected in the agreements' texts. These include both general and specific exceptions to commitments as well as reservations. The flexibility indicator ranges from $\circ$ to 8 .

\section{Consumer Protection}

An important and more specific flexibility instrument consists of explicitly foreseeing ways to protect consumer interests. This indicator ranges from $\circ$ to 4 and includes elements of individual rights in relation to data protection, Internet Governance principles, data localization measures or addressing spam.

\section{Non-discrimination}

This indicator measures how much attention treaty drafters have directed to general principles related to non-discrimination, such as treating domestic and foreign actors equally as well as following the most favoured nation (MFN) clause. On top, we add references to the WTO commitments and the need for technology neutrality. The higher the indicator, the more negotiators embed trade agreements within the multilateral trading system aiming for more consistency across treaties. ${ }^{16}$ The indicator ranges from $\circ$ to 7 .

\section{Regulatory Cooperation}

The final indicator measures the degree to which treaty drafters advocate various forms of regulatory cooperation. We compile commitments that call for cooperation on transparency, international alignment in regulatory fora or working together on

15 Baccini et al., note 6.

${ }^{16}$ T. Allee and M. Elsig, 'Are the Contents of International Treaties Copied-and-Pasted? Evidence from Preferential Trade Agreements', International Studies Quarterly 63 (2019), $603-613$. 
cybersecurity issues. In addition, we explore whether the treaty mentions working groups or committees to implement the electronic commerce commitments. This indicator is a proxy for how much regulatory cooperation is foreseen in the treaty text. The indicator ranges from $\circ$ to 13 .

\section{DESCRIBING TRENDS AND PATTERNS IN DIGITAL}

TRADE GOVERNANCE

In this section we discuss briefly the evolution of PTAs over time. We provide some descriptive statistics based on the indicators developed earlier, derive a better idea about who the rule-makers are and explore a number of bivariate relations which are suggestive about potential interdependence between design features, but also between treaty content and domestic practice.

The first agreement referring to electronic commerce was signed in 2000 . Therefore, we deal with a rather novel issue area for trade regulation. There are no observations prior to 2000 while discussions within the WTO had been going on for a while. This is suggestive to the possibility that governments have prioritized the multilateral arena while then slowly turning to PTAs either because of lack of progress in the WTO (see Figure 2.1), or because of learning effects and development of various government strategies and potentially implicit models. Figure 2.2 shows the steady increase of e-commerce provisions, e-commerce chapters and provisions on free data flow both in absolute numbers and relative to the number of PTAs signed per year.

In total, we have identified ninety-nine PTAs that have at least one data-related provision. Table 2.1 provides the summary statistics for the different indicators outlined earlier and confirms the notion of considerable heterogeneity among PTAs.

In the following figures, we zoom into a selection of indicators and illustrate their evolution over time. Figure 2.3 shows the Scopes indicator, which captures the number of words related to the regulation of e-commerce and data flows. The median and range of the count of words varies considerably over time. We also observe a number of outliers, including Jordan-Singapore 2004, the Central European Free Trade Agreement (CEFTA) in 2006 and Australia-Japan 2015. The latter one is an outlier for that year but is following an upward trend. We also observe large variation in the years 2016-2018.

In Figure 2.4 we show the second scope indicator, based on the number of provisions related to the regulation of e-commerce and data flows. Again, we observe that scope increases; however, this does not occur gradually. In most years, we notice a considerable range of provisions as well as a number of outliers. Compared to other PTAs signed in 2006, CEFTA has only few provisions related to the regulations of e-commerce and data flows. In 2007, the same is true for the PTA between Japan and Thailand. In contrast, the Panama-US PTA in 2007 includes a rather 
TABLE 2.1. Summary statistics on the indicators

\begin{tabular}{lrrrrr}
\hline \hline Variable & Obs & Mean & Std. Dev. & Min & Max \\
\hline Scope 1 & 99 & 793.2 & 669.2 & 17 & 3,209 \\
Scope 2 & 99 & 22.9 & 10.5 & 2 & 46 \\
Depth & 99 & 6.5 & 3.5 & 0 & 15 \\
Flexibility & 99 & 3.3 & 2.1 & 0 & 8 \\
Consumer protection & 99 & 1.6 & 0.8 & 0 & 3 \\
Non-discrimination & 99 & 3.0 & 1.7 & 0 & 6 \\
Regulatory cooperation & 99 & 4.3 & 2.7 & 0 & 12 \\
\hline
\end{tabular}

Source: Authors' calculation based on the TAPED database.

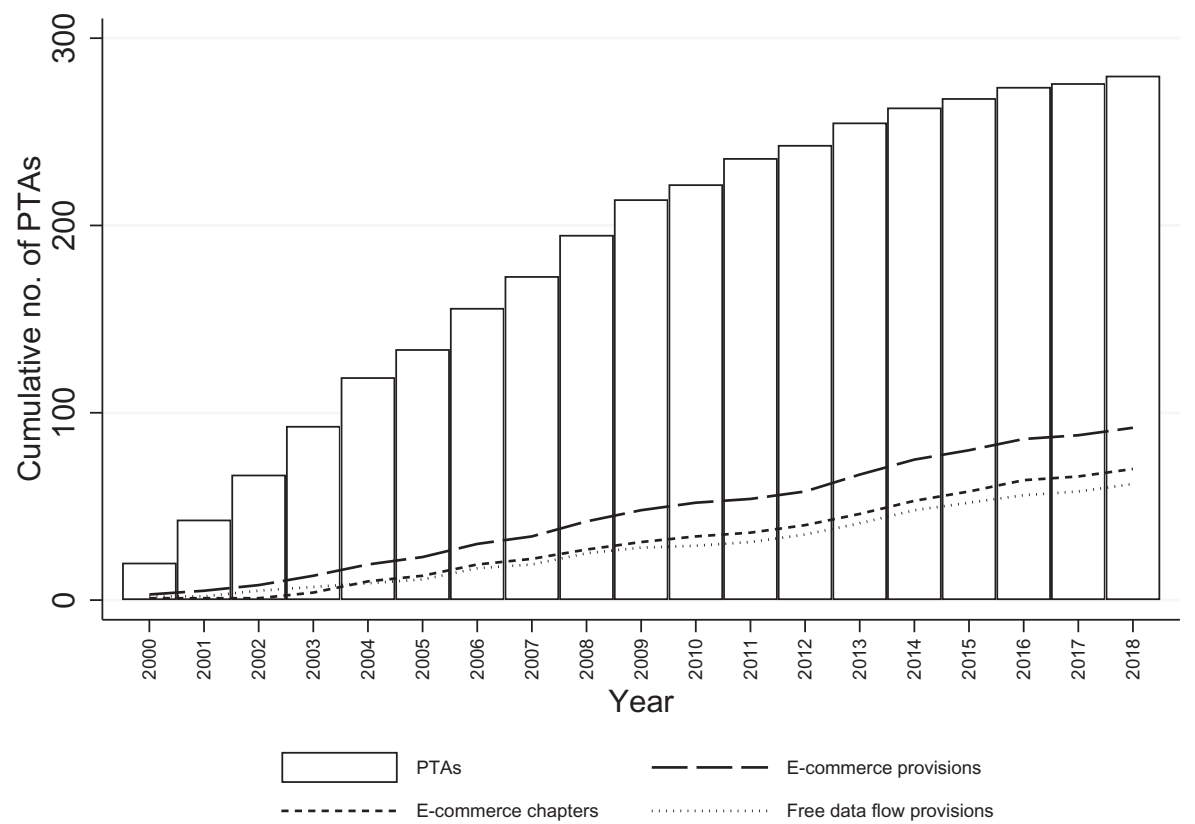

FIGURE 2.2. The evolution of e-commerce and data flow regulation in PTAs, 2000-2018. Source: Authors' illustration based on the TAPED database. The TAPED database traces all data-relevant norms in trade agreements and is available at https://unilu.ch/taped. See also M. Burri and R. Polanco, 'Digital Trade Provisions in Preferential Trade Agreements: Introducing a New Dataset', Journal of International Economic Law 23 (2020), 187-220.

large number of provisions on this topic. The PTA between Colombia and Costa Rica presents the top outlier in 2013, the PTA between Central America and the European Free Trade Association (EFTA) the bottom outlier. Malaysia-Turkey and Canada-Ukraine present the two outliers in 2014 and 2016, respectively.

Over time, we also detect an increase in the depth (Data Flow Facilitation) indicator (Figure 2.5). Following the above trend, the 2006 CEFTA agreement 


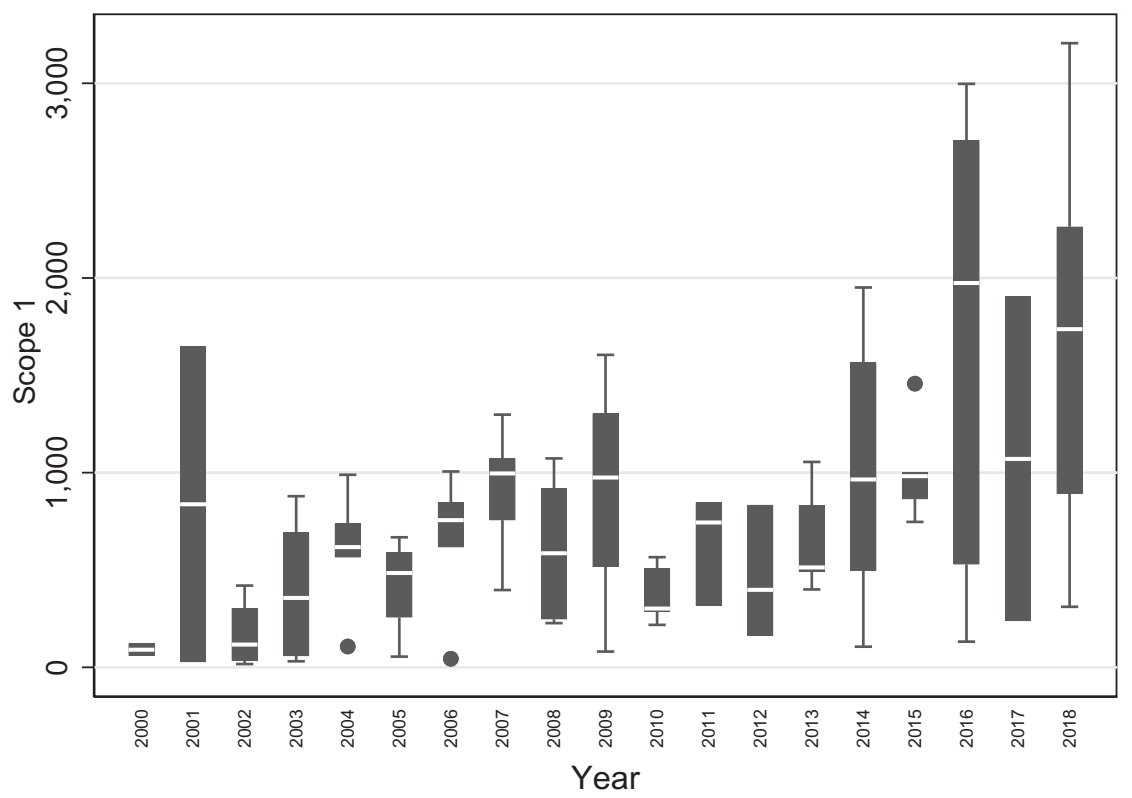

FIGURE 2.3. The Scope 1 indicator, 2000-2018.

Source: Authors' illustration based on the TAPED database.

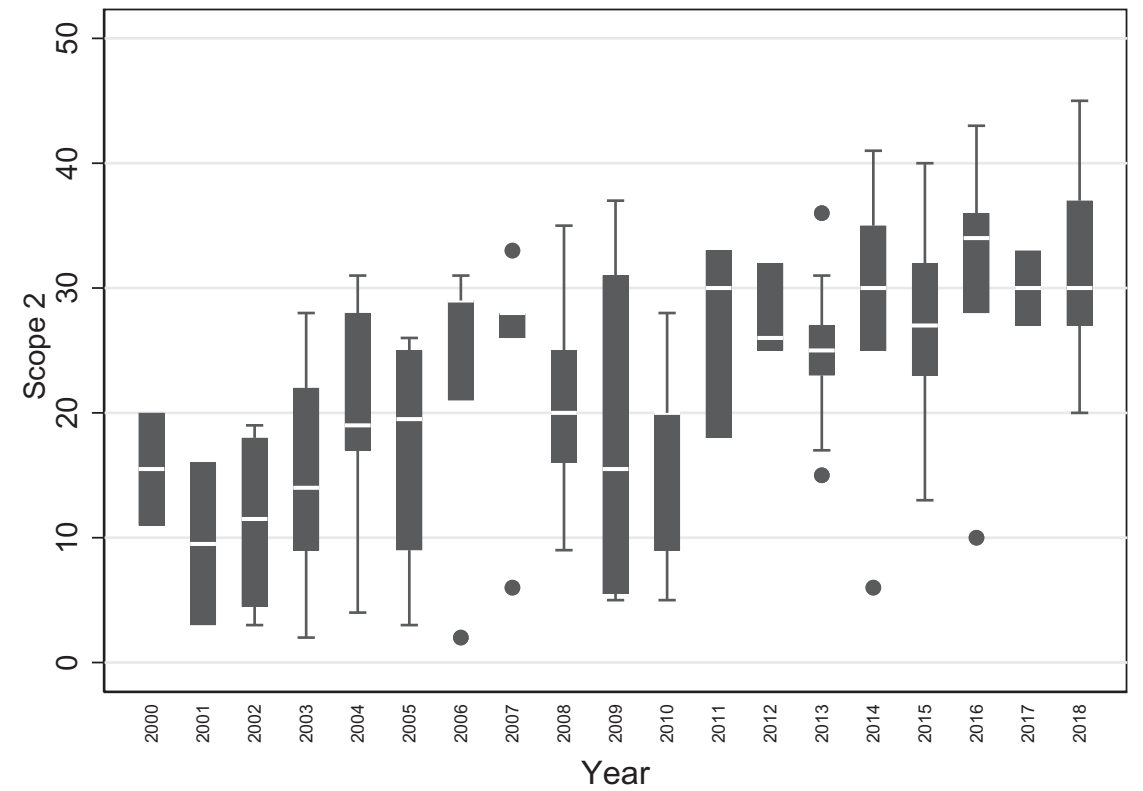

FIGURE 2.4. The Scope 2 indicator, 2000-2018.

Source: Authors' illustration based on the TAPED database. 


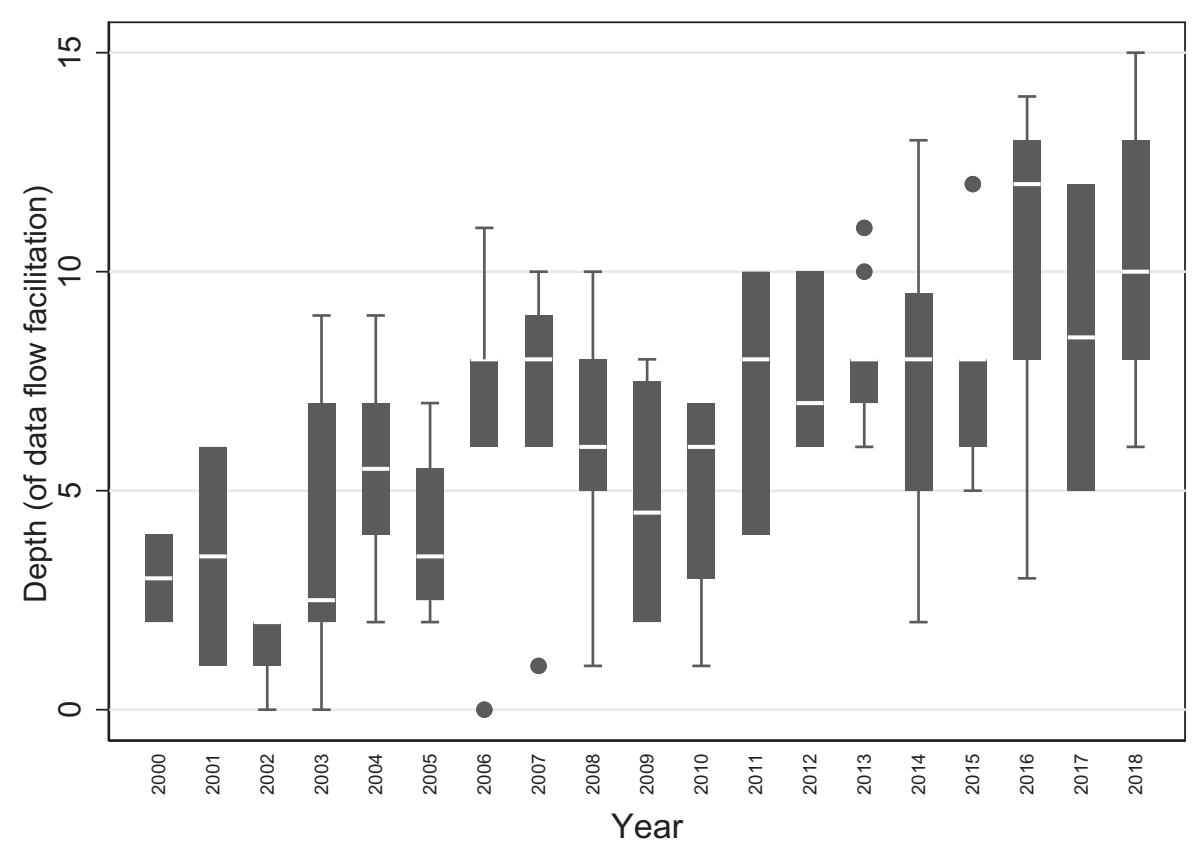

FIGURE 2.5. The depth indicator, 2000-2018.

Source: Authors' illustration based on the TAPED database.

and the 2007 Japan-Thailand PTA indicate substantially shallower commitments than other agreements in these respective years. The outlier PTAs having substantially deeper commitments in 2013 than other agreements signed in that year are Colombia-Costa Rica as well as Colombia-Panama, most likely inspired by their commitments in one of their recent trade agreements with a rule-maker. In 2015, we observe in Mongolia's first ever PTA with Japan also deeper commitments in terms of data flow facilitation.

Turning to our flexibility indicator (Figure 2.6), we observe that already between 2004 and 2008 PTAs included higher levels of flexibility. Again, CEFTA presents the outlier in 2006, which is not surprising as it also scored low on scope and depth. The bottom outlier in 2015 is the PTA between Canada and Ukraine, which might be explained by the low trade flows in goods and services with substantial data content between the two countries. The top outlier in the same year is the PTA between Australia and Singapore, which could be a result of two countries with usually deep agreements.

\section{E OF RULE-MAKERS AND CENTRAL ACTORS}

The previous sections discussed the various indicators and illustrated their variation over time. In this section, we take a closer look at the signatory countries. In total, 


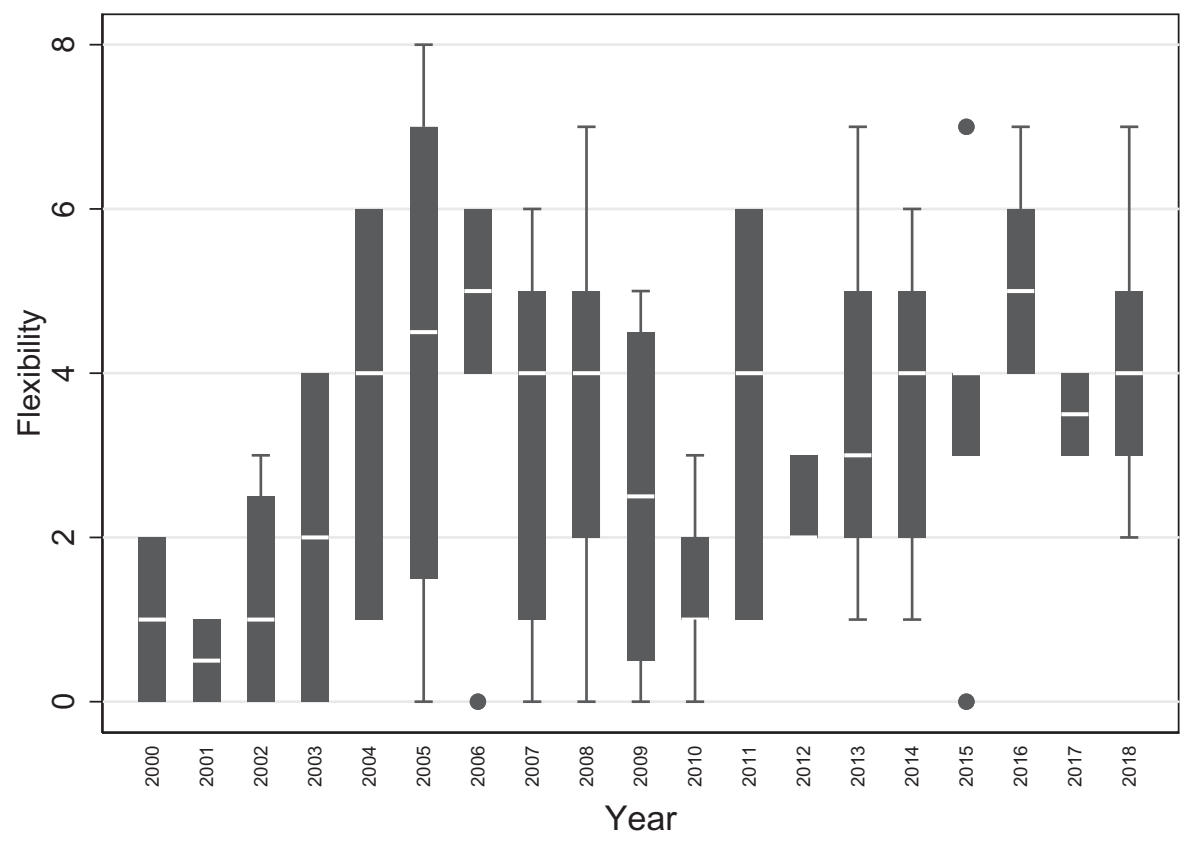

FIGURE 2.6. The flexibility indicator, 2000-2018.

Source: Authors' illustration based on the TAPED database.

eighty-two countries (counting the EU as one actor) are involved in the ninety-nine PTAs which have data flow-related provisions since 2000. As illustrated in Figure 2.7, there is considerable heterogeneity in terms of the number of PTA partners by signatory and the degree of scope measured by the number of provisions. Since 2000, the EU has signed eighteen PTAs with thirty-eight partner countries and, on average, included twenty-three provisions on e-commerce and data flows. Mongolia (MGN) has only signed one PTA (with Japan). In this PTA, however, there are forty provisions on e-commerce and data flows. The United States has signed fewer agreements than the EU, but on average their scope is substantially higher. We also observe that the average scope of agreements with European countries is significantly lower than treaties with countries of the Americas. Oceania is also above average in terms of scope. Finally, African signatories of PTAs are not yet addressing data flow-related provisions. This is surprising given the potential of e-commerce for developing countries.

To illustrate this network of PTAs, we combine the average Scope 2 indicator and the count of PTA partner countries for each signatory country and represent this in Figure 2.8 using instruments of network analysis. In this network, the size of each country is proportional to its weighted centrality. That is, the size of each country is proportional to the product of the number of PTA partners and the average number 


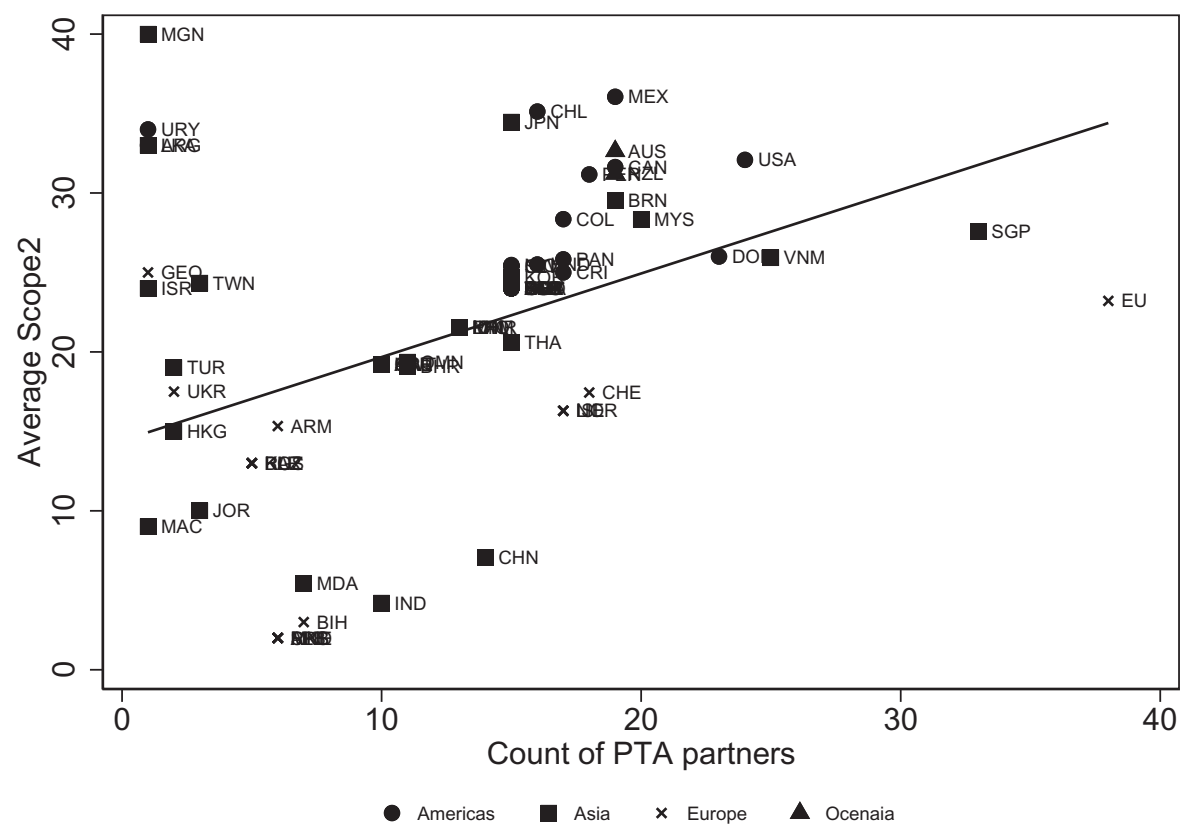

FIGURE 2.7. The Scope 2 indicator and the count of PTA partners.

Source: Authors' illustration based on the TAPED database.

of provisions on e-commerce and data flows included in all its PTAs. The width of the links is proportional to the number of e-commerce and data flow provisions in a given PTA. Figure 2.8 highlights that there are some countries that are central to this PTA network and therefore potentially influential in diffusing certain regulatory models on e-commerce and data flows. The European Union, the United States and Singapore stand out, but also other countries, such as Australia, Canada or Mexico, are pictured as central actors.

To investigate the patterns that can be graphically observed in the earlier network, we zoom into the subset of PTAs that have not only at least one provision on ecommerce and data flows but a full chapter. Out of the ninety-nine PTAs signed since 2000 , seventy-two have a chapter related to e-commerce and data flows. Seven of these PTAs are signed between Latin American countries and only available in Spanish, leaving us with sixty-three PTAs that are available in the English language. Since Singapore and Australia renewed their 2003 PTA in 2016, we only include the latter PTA in this analysis - leaving us with a subset of sixty-two PTAs.

Relying on text-as-data analysis, we compare these sixty-two PTA chapters in the English language to detect potential patterns, more precisely, by employing the plagiarism software WCopyfind to measure the textual overlap between the PTA chapters. The programme allows for a number of refinements. We follow the 


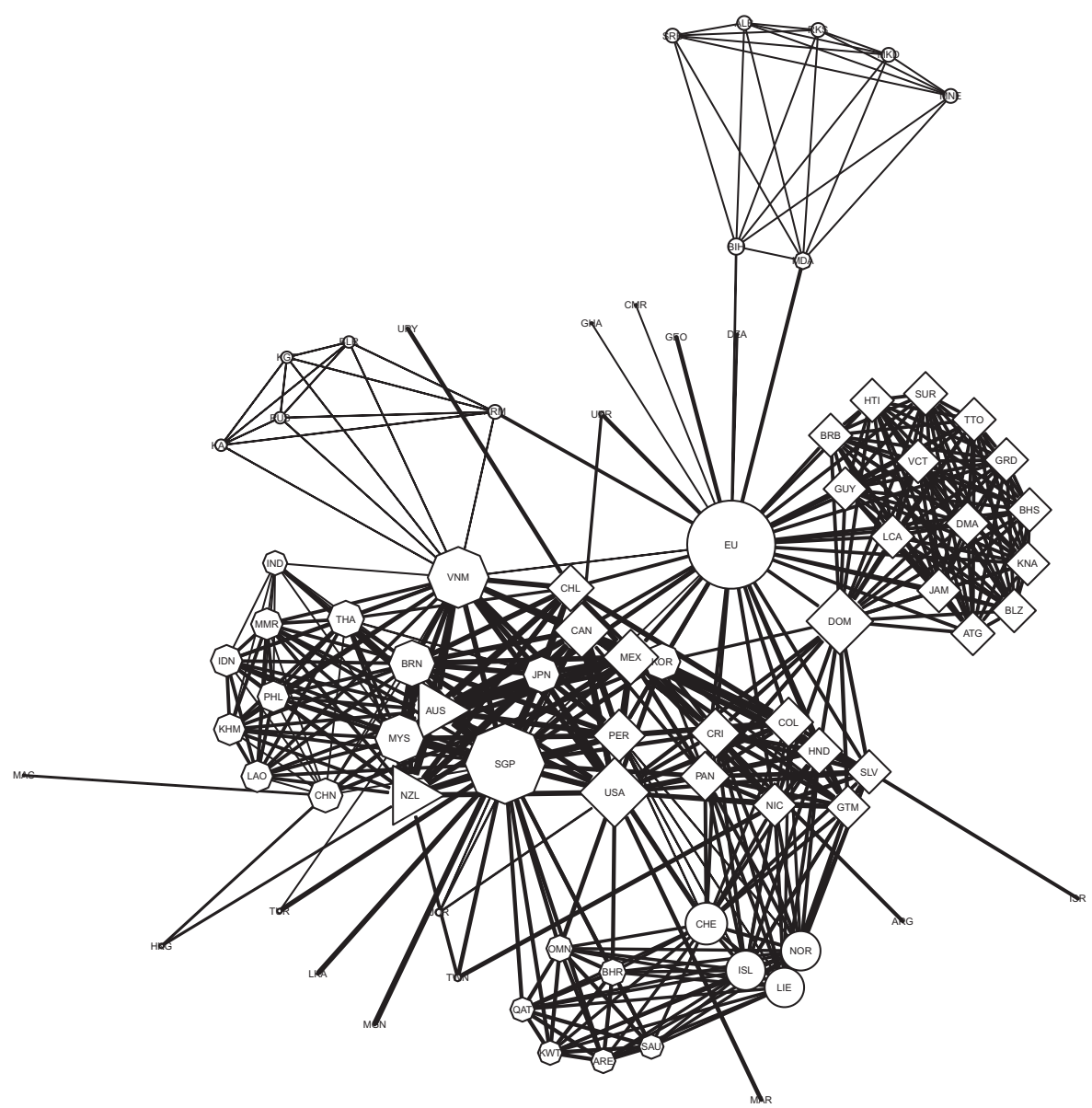

FIGURE 2.8. The network of PTAs regulating e-commerce and data flows.

Source: Authors' illustration based on the TAPED database. Note: Blue-Asia, White-Americas, RedEurope, Green-Oceania.

convention to use a minimum of six consecutive identical words for a match. ${ }^{17}$ All punctuation, outer punctuation, numbers, letter case and non-words are ignored. It should be pointed out that WCopyfind only reports the PTAs that have a minimum of matches between PTAs. In our case, the PTAs between Jordan and Singapore (2004), Canada and Jordan (2009), the Eurasian Economic Union (EAEU) and

${ }^{17}$ T. Allee and A. Lugg, 'Who Wrote the Rules for the Trans-Pacific Partnership?', Research and Politics 3 (2016), 1-9; T. Allee, M. Elsig and A. Lugg, 'Is the European Union Deal with Canada New or Recycled? A Text-as-Data Approach', Global Policy 8 (2017), 246-252; T. Allee, M. Elsig and A. Lugg, "The Ties between the World Trade Organization and Preferential Trade Agreements: A Textual Analysis', Journal of International Economic Law 20 (2017), $333-363$. 


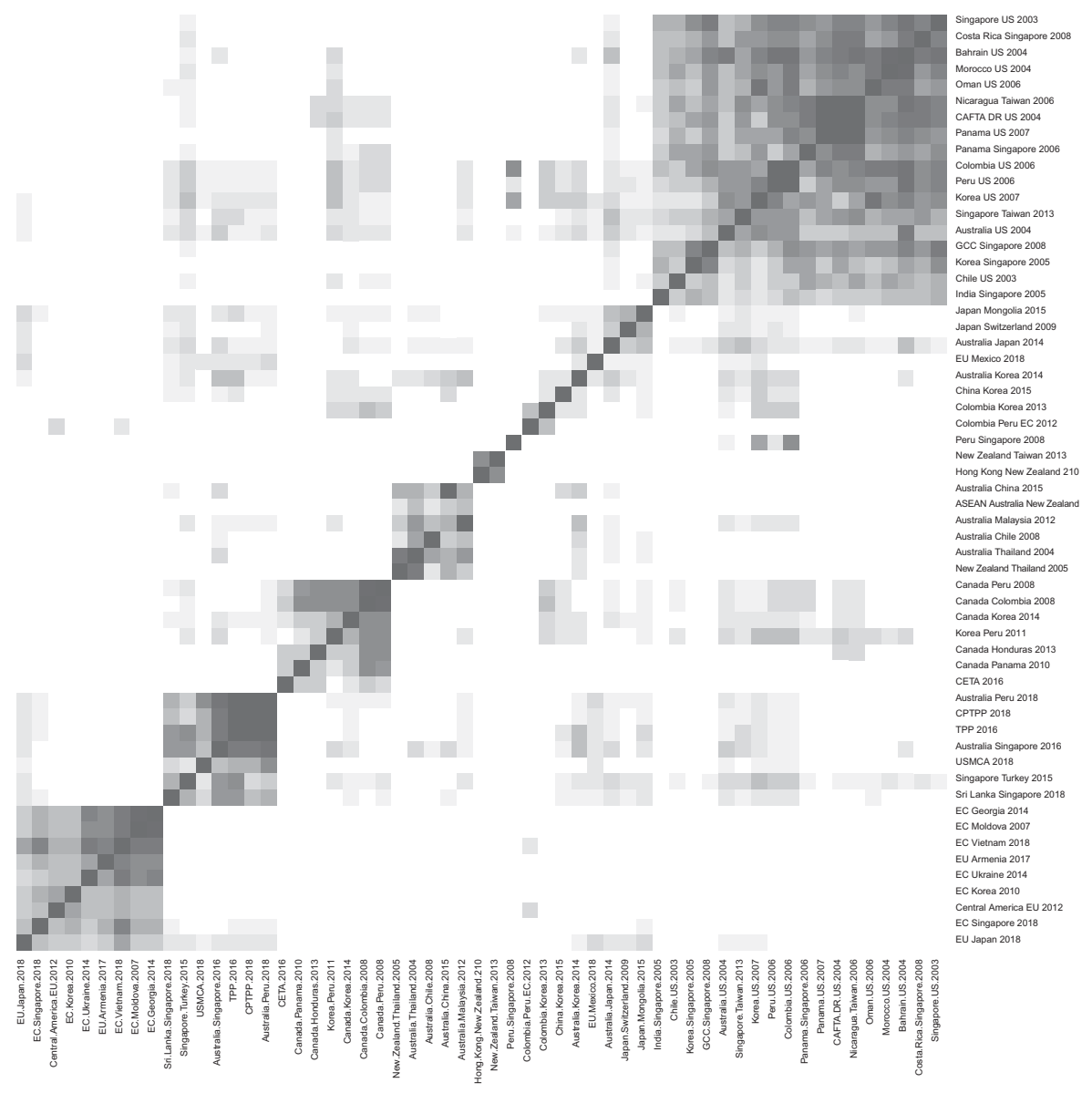

FIGURE 2.9. A heat map on text-as-data analysis of e-commerce and data flow chapters in PTAs.

Source: Authors' illustration based on PTA texts collected for the TAPED database.

Vietnam (2015) and between Canada, and the Ukraine (2016) appear to have too little overlap with the other PTAs and were consequently dropped by the programme.

The heat map (Figure 2.9) provides a number of interesting insights. In terms of interpretation, the map colours the squares darker, the higher the textual overlap between the e-commerce and data flow chapters of two respective PTAs is. In Figure 2.9, the PTA chapters are hierarchically clustered, meaning PTAs are grouped together into clusters. The clusters and their PTAs are fairly distinct from each other and the PTAs within a cluster are broadly similar to each other. Figure 2.9 suggests that there are five main clusters. The top right cluster indicates that the United States and Singapore take similar approaches when designing their 
e-commerce chapters. This is likely to be the case because they have signed a PTA with one another in 2003 . Out of the eighteen PTAs that are identified to be in this cluster, the United States and Singapore have signed eleven and seven, respectively. Interestingly, their PTA partners overlap only partly. While the United States and Singapore both have PTAs with South Korea and Panama, the other PTA partners are distinct. It is also interesting to note that Singapore already signed its PTAs with South Korea and Panama in 2005 and 2006 respectively, while the United States only signed its agreements with the two countries in 2007. The second PTA cluster can be found in the centre of Figure 2.9. These six PTAs appear to be following the Australian approach. Indeed, Australia is a signatory of five of these PTAs; the sixth PTA is between New Zealand and Thailand in 2004. Down and to the left is the third distinct cluster of PTAs. Out of the seven PTAs identified to be in this cluster, Canada has signed six. Somewhat surprisingly, the 2011 PTA between South Korea and Peru seems to follow a similar approach to the Canadian PTAs in this cluster. Figure 2.9 also shows that the Comprehensive Economic and Trade Agreement (CETA) between the Canada and the EU is closer to previous Canadian agreements than to EU agreements (the cluster at the bottom left). The second last cluster includes the Trans-Pacific Partnership Agreement (TPP, 2016) and the Comprehensive and Progressive Agreement for Trans-Pacific Partnership (CPTPP, 2018), as well as a number of other agreements that the (CP)TPP members have signed. Interestingly, the e-commerce chapter of the recently negotiated agreement between the United States, Mexico and Canada (USMCA, 2018) is also found to be very close to the (CP)TPP. The last cluster in the bottom left corner of Figure 2.9 includes recent agreements by the EU. Overall, the text-as-data analysis presented helps detect the small group of countries which seem to be the rule-makers in the area of digital trade.

\section{F ZOOMING IN ON THE RULE-MAKERS}

In this section we compare these rule-makers by focusing on the number of provisions (Scope 2) and differentiate these provisions in terms of their legal language and overall 'bindingness'. The legal language provides clues as to whether we expect more or less obligation based on words such as 'should', 'shall', or 'may'. We differentiate between high and low obligation. Figure 2.10 provides an overview for five identified rule-makers (United States, EU, Australia, Canada and Singapore). The figure shows the average and maximum count of total provisions, as well as the average and maximum count of that have a high level of bindingness. The maximum scores might be more intuitive to interpret as countries potentially do not negotiate in their future agreements commitments below the ones already agreed upon.

For scope and depth, we observe that for the so-called rule-maker group, roughly half of all commitments are phrased in legal terms that suggest high obligation. In 


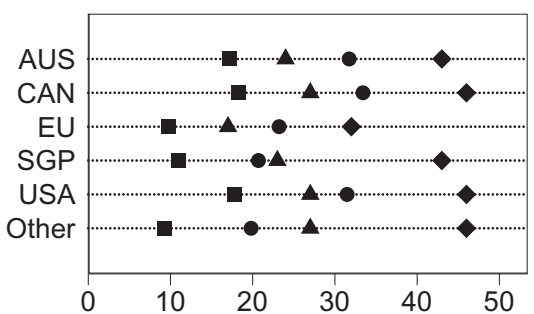

Count of Scope2 provisions

- All (mean)

- All (max)

- High (mean)

4 High (max)

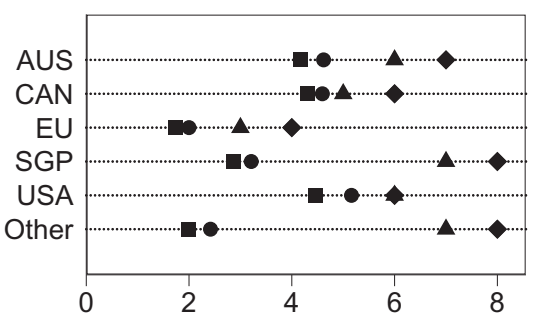

Count of Flexibility provisions

- All (mean) $\bullet$ All (max)

- High (mean) $\Delta$ High (max)

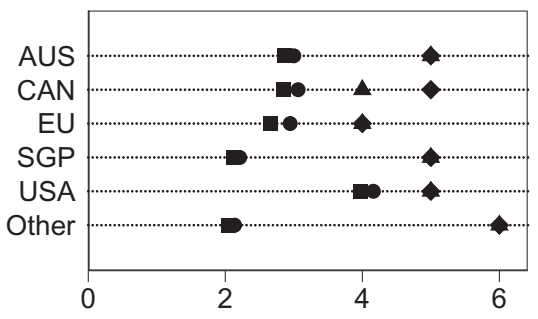

Count of Non-discrimination provisions

- All (mean)

All (max)

- High (mean)

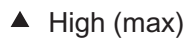

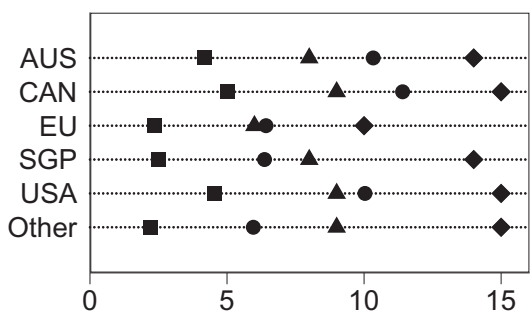

Count of Depth provisions

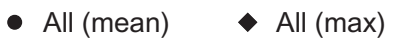

- High (mean) $\Delta$ High (max)

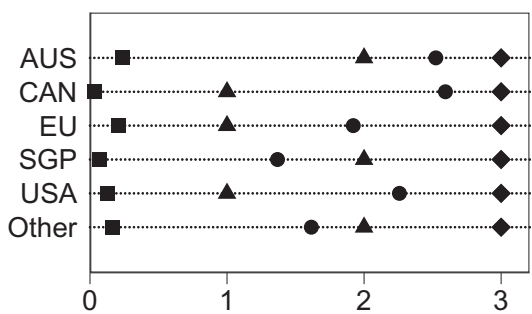

Count of Consumer protection provisions

- All (mean) $\bullet$ All (max)

- High (mean) $\Delta$ High (max)

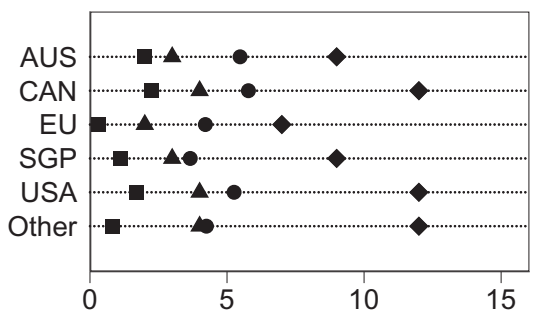

Count of Regulatory cooperation provisions

- All (mean) $•$ All (max)

- High (mean) $\Delta$ High (max)

FIGURE 2.10. Dot plots for the indicators.

Note: In the figure on non-discrimination provisions, High(max) is equal to All(max) for Australia, the EU, Singapore, the United States and others, which is why only the All (max) indicator is shown.

Source: Authors' illustration based on the TAPED database. 
terms of the average and maximum values for scope and depth, the EU scores lower than the other rule-makers as well as other countries. We observe a similar pattern for the flexibility indicator. Of the rule-makers, it is in particular Singapore which includes a considerable number of flexibility-related provisions. For the indicator related to consumer protection, we in particular detect that Singapore and Australia agree on legal language that signals higher obligation and therefore allows for stronger rights to protect individuals. The non-discrimination provisions are overwhelmingly commitments which come with high obligation based on the reading of the legal language. By contrast, when we turn to regulatory cooperation, we observe that the legal wording signals rather low levels of obligation, therefore these features of the treaties are practically not enforceable in case of disagreement among PTA members.

\section{G EXPLORING EXPLANATIONS FOR TREATY DESIGN}

In this section we provide graphical descriptions of a number of bivariate relations to address potential explanations for variation in PTA design. The first group of graphs (Figure 2.11) addresses the question as to whether PTA design is largely endogenous; in other words, many of the design features are related to each other, as suggested by some authors. We focus on the depth variable and explore how this is correlated with other indicators. First, we see that scope and depth are highly correlated, which is not surprising. PTAs that are paying more attention to data-related issues are also deeper. Second, deeper agreements are also going hand in hand with PTAs that advocate regulatory cooperation. This could also be interpreted as negotiators are forward-looking, promising to engage in regulatory discussion to accompany the rapidly changing regulatory environment. Deeper agreements are also more flexible, and provide for more consumer protection rights and non-discrimination clauses.

Another set of explanations can be situated at the domestic level and relates to a different set of questions: To what degree are domestic policies mirrored in international law commitments? Are countries using international law as a commitment device to bring about domestic regulatory change or are we rather witnessing a screening effect in which commitments largely reflect domestic practice suggesting some cheap talk in relation to signing agreements? ${ }^{18}$

To address such questions, we discuss how PTA design relates to domestic digital policies. We rely on the recently published Digital Trade Restrictiveness Index (DTRI) by the European Centre for International Political Economy (ECIPE). The DTRI covers a range of fiscal, establishment, data and trading restrictions related to digital trade for sixty-four economies worldwide. The index ranges between zero and one, where zero indicates a fully open digital economy and one indicates a virtually closed digital economy. Between the TAPED database and the

${ }^{18}$ J. von Stein, 'Do Treaties Constrain or Screen? Selection Bias and Treaty Compliance', American Political Science Review 99 (2005), 611-622. 

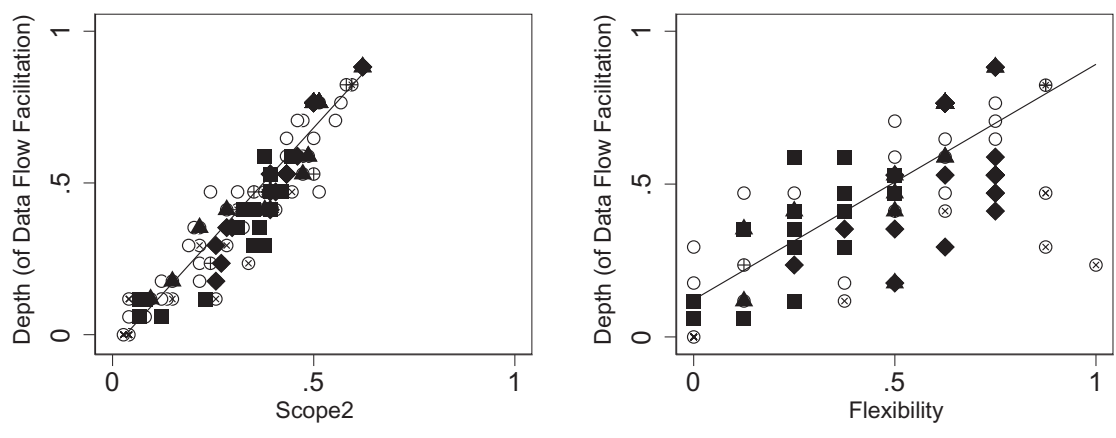

$O$ Other USA EU $\boldsymbol{\Delta} \mathrm{CAN} \times \mathrm{SGP}+\mathrm{AUS}$

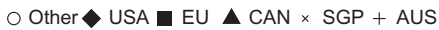
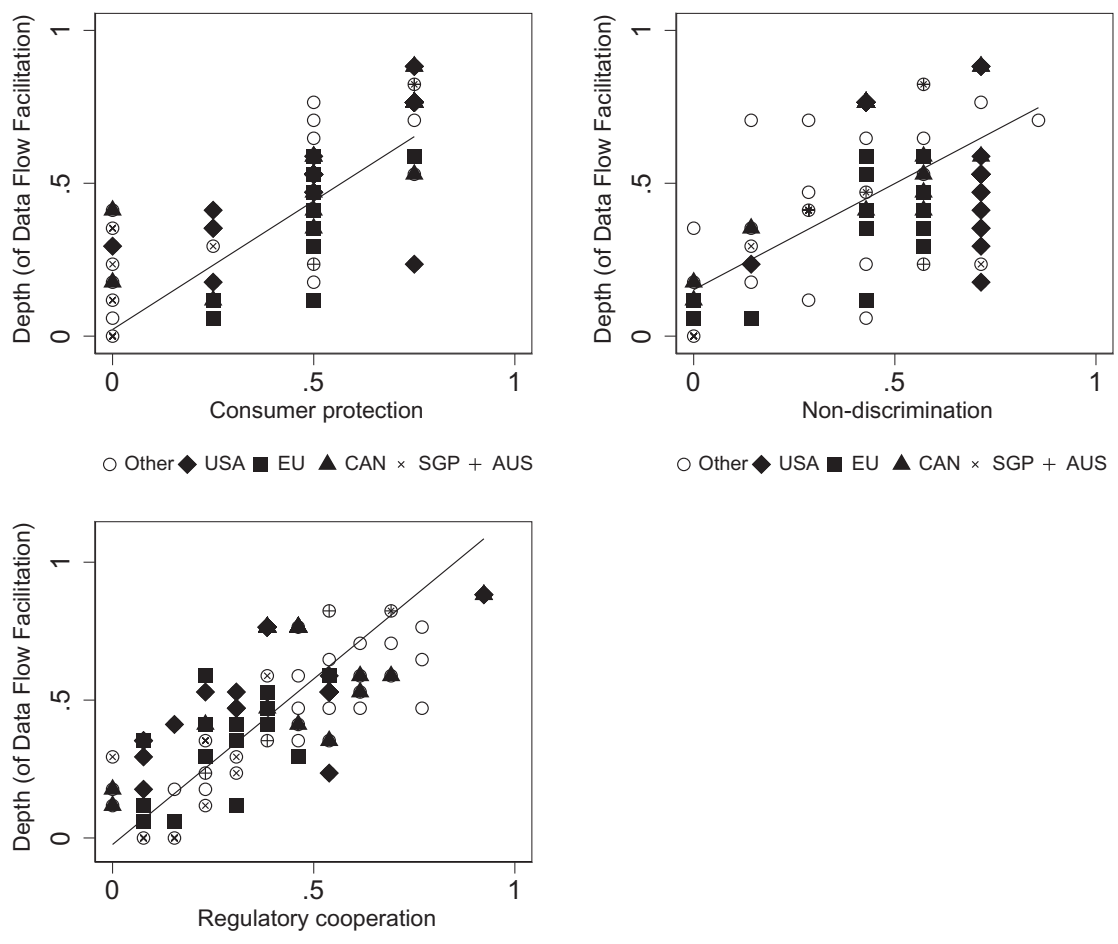

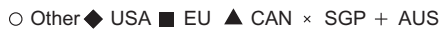

FIGURE 2.11. The depth in relation to the other indicators.

Source: Authors' illustration based on the TAPED database.

DTRI, we have an overlap of thirty-one countries. ${ }^{19}$ Figure 2.12 illustrates how our main indicators relate to the DTRI. All indicators are negatively correlated with the

19 The relatively little overlap is due to the fact that the DTRI includes individual member states which in TAPED are grouped as EU. 

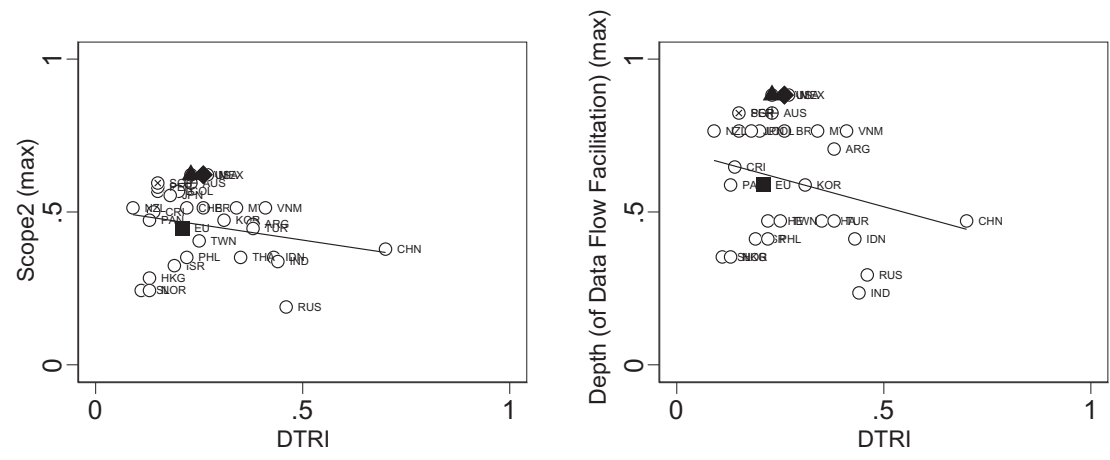

$O$ Other USA $\square$ EU $\triangle \mathrm{CAN} \times \mathrm{SGP}+\mathrm{AUS}$

$O$ Other USA EU $\triangle \mathrm{CAN} \times \mathrm{SGP}+\mathrm{AUS}$
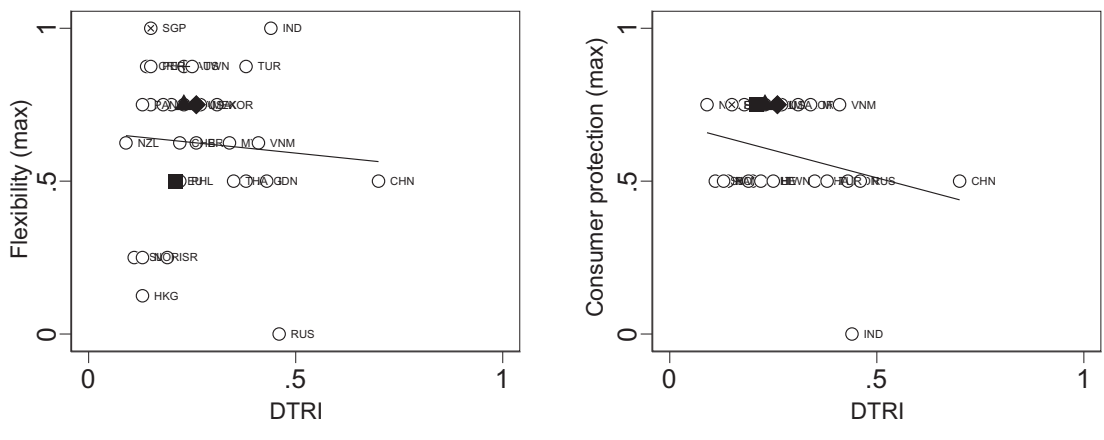

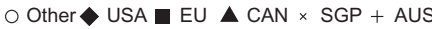

$O$ Other USA $\square \mathrm{EU} \boldsymbol{A} \mathrm{CAN} \times \mathrm{SGP}+\mathrm{AUS}$
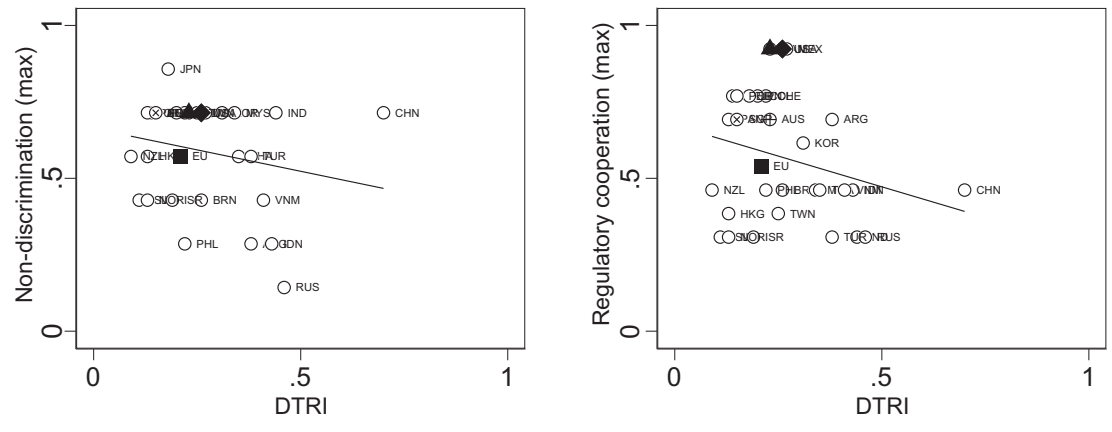

O Other USA EU $\boldsymbol{\Delta}$ CAN $\times$ SGP + AUS

FIGURE 2.12. PTAs and digital trade restrictiveness.

Source: Authors' illustration based on the TAPED and the DTRI databases.

DTRI. ${ }^{20}$ As for those indicators that are about scope, depth and various obligations, a negative correlation casts doubts about prima facie evidence that a commitment

20 Scope 2: -0.2208 , Depth: -0.2483 , Flexibility: -0.0746 , Consumer protection: -0.2892 , Nondiscrimination: -0.2132 , Regulatory cooperation: -0.2639 . 
story is at play here. More interesting are downward trends for flexibility and consumer protection; countries with lower restrictions aim for more flexibility. This would rather suggest that these countries aim to keep policy space in this area, whereas countries with higher restrictions paradoxically demand less flexibility providing some support for the idea of a commitment device. Overall, we also observe that the rule-makers, with the exception of the EU, are substantially above the trend lines.

\section{H CONCLUSION}

Data flow provisions have entered the universe of PTAs in the past fifteen years, although, only a third of all PTAs have commitments related to this area. This chapter presented a number of indicators related to PTA design and has mapped the design evolution over time. Letting the data speak, we discovered a number of leading actors (rule-makers) and sets of overlapping models of treaties based on textual analysis. However, we seem to be at the beginning of a period where datarelevant provisions will only increase in importance as many classic trade and traderelated provisions, such as tariffs, become relatively less important.

What are the next steps in understanding design and design variation in the domain of digital trade? First, research may explore explanations to account for variation in design based on political economy models and arguments rooted in the international relations literature; for instance, what roles do commitment concerns or power asymmetry play in agreeing upon new rules? Which interest groups are pivotal for pushing new rules? How does the competition between exporter interests and consumer protection interests define government positions entering into PTA negotiations? Second, research should pay more attention to the evolving competition among models that are being developed, in particular starting with the CPTPP and how this will affect the creation and promotion of other models, such as that of the EU. Are these models complementary or are they creating regulatory barriers? Related to this, it can be asked how leading promoters of models use PTAs to diffuse their preferred models and what the impacts on non-PTA members are when they negotiate PTAs. It would be also pertinent to explore to what degree new domestic initiatives, such as the EU General Data Protection Regulation, impact on PTA design and push for updating existing PTAs. ${ }^{21}$

Finally, the following questions need to be raised: What is the impact of these commitments on state behaviour? How do they assist in creating new domestic

${ }^{21}$ See, e.g., M. Burri, 'Privacy and Data Protection', in D. Bethlehem et al. (eds), The Oxford Handbook on International Trade Law, nnd edn (Oxford: Oxford University Press, 2021). 
policies and laws on the role of data in trade and how do they inhibit government action to restrict trade in light of consumer protection concerns? Also, more generally, how do these commitments directly or indirectly impact trade flows in goods and services and investment-location decisions for firms with large data components in their business models? 